\title{
Echocardiographic Correlation between Right Ventricular Function and Left Atrial Volume
}

\author{
Liz Andréa Villela Baroncini, ${ }^{\circledR}$ Lucas José Lira Borges, ${ }^{2}$ Ana Cristina Camarozano, ${ }^{1 \oplus}$ Daniela de Castro Carmo, ${ }^{2 \odot}$ \\ Rubens Zenobio Darwich, ${ }^{2}$ Jeronimo Antonio Fortunato Junior ${ }^{2}$ \\ Instituto Saber e Aprender, ${ }^{1}$ Curitiba, $P R$ - Brazil \\ Hospital da Cruz Vermelha - Cruz Vermelha Brasileira - Filial do Estado do Paraná, ${ }^{2}$ Curitiba, $P R$ - Brazil
}

\begin{abstract}
Background: Few reports exist on the relationship of the left ventricular diastolic dysfunction (LVDD) with its most important features including enlargement of the left atrium and left ventricular hypertrophy (LVH), and with the right ventricular (RV) function.
\end{abstract}

Objective: To determine the correlation between the left atrial size and the RV function and dimensions in patients with and without LVDD and LVH.

Methods: Fifty patients were included, $25(40 \%$ men) of them with LVDD, aged $67.1 \pm 10.6$ years (study group) and 25 without LVDD (52\% men) aged $49.9 \pm 16.3$ years (control group). Patients underwent transthoracic echocardiography with evaluation of the left atrial size and volume (LAV), LVDD, LVH, and RV function and dimensions. P-values $<0.05$ were considered statistically significant.

Results: LAV > $34 \mathrm{~mL} / \mathrm{m}^{2}$ and left atrial size $>40 \mathrm{~mm}$ were associated with lower absolute values of tricuspid annular plane systolic excursion (TAPSE) and RV lateral $S^{\prime}$ ( $p \leq 0.001$, Pearson's correlation coefficient -0.4 and -0.38 , respectively) in the study group. Patients in the study group showed higher incidence of $\operatorname{LV}(p=0.02)$ and greater left atrial diameter ( $p=0.03)$ compared with the control group. In addition, greater left atrial diameter $(p=0.02)$ and LAV $(p=0.01)$ values were found in patients with LVDD grade II compared with LVDD grade I.

Conclusions: The present study determined, for the first time, the correlation of left atrial enlargement with progressive RV dysfunction in patients with LVDD. (Arq Bras Cardiol. 2019; 112(3):249-257)

Keywords: Ventricular Dysfunction Right; Atrial Function/Physiology; Echocardiography/Methods; Blood Pressure; Heart Failure; Stroke Volume.

\section{Introduction}

Morphological and functional interdependence between the two ventricles may be explained by three mechanisms: (1) increase in right ventricular (RV) end-diastolic pressure in response to an increase in the left ventricular (LV) volume; (2) increased LV filling pressure inducing mechanical stress of the muscle fibers common to both ventricles; and (3) humoral factors, including catecholamines, that may regulate ventricular hypertrophy in response to pressure overload of one of the ventricles. ${ }^{1-4}$ The function and dimensions of the right ventricle are directly associated with the LV function. Dilatation of the right ventricle and reduction of its contractile strength is usually found in advanced stages of LV dysfunction, reinforcing the close relationship between the two ventricles. ${ }^{5-7}$ It is known that in heart failure patients with reduced LV ejection fraction both

Mailing Address: Liz Andréa Villela Baroncini •

Rua Buenos Aires, 764, apt. 601. Postal Code 80250-070, Batel, Curitiba, PR - Brazil

E-mail: lizavb@cardiol.br, lizandreabaroncini@hotmail.com Manuscript received February 25, 2018, revised manuscript May 25, 2018, accepted July 23, 2018

DOI: $10.5935 / a b c .20190042$ ventricular dynamic and pressures are altered, affecting the size and function of other cardiac chambers. However, few reports exist about the relationship between heart failure with preserved LV ejection fraction and increased RV dimensions with reduced systolic function fraction. ${ }^{4}$ Also, there are few reports on LV diastolic dysfunction and related findings, such as enlargement of the left atrium (LA), LV hypertrophy (LVH), and their influence on systolic function and RV volume. The LA seems to reflect LV diastolic dysfunction (LVDD), since the parietal tension caused by increased filling pressures leads to dilation of the atrial chamber. ${ }^{4}$ In addition, there are no studies specifically evaluating the influence of LA size and LA volume on diameter and function of the right ventricle. Therefore, the aim of the present study was to evaluate the correlation of left atrial volume (LAV) and left atrial diameter with the presence of LVH and RV function and diameter in patients with and without LVDD.

\section{Methods}

\section{Patients}

This was a cross-sectional cohort study. We studied a convenience sample of 50 consecutive outpatients that underwent transthoracic echocardiogram (TTE) with 
quantification of LV diastolic function, left atrial diameter and LAV, and RV systolic function and diameter at public healthcare centers. Patients on both sexes, aged older than 18 years, and of any ethnicity, referred for TTE by assistant physicians for any cause were selected. Exclusion criteria were presence of global (ejection fraction $<52 \%$ for men and $<54 \%$ for women) or segmental LV systolic dysfunction, infiltrative diseases, pericardial diseases, chronic obstructive pulmonary disease, asthma, moderate-to-severe valve diseases with hemodynamic repercussion, interatrial or interventricular septal defects, conditions that impaired the analysis of LV diastolic function (valve diseases with hemodynamic repercussion, atrial fibrillation at the electrocardiogram, definite pacemaker), presence of complete left or right bundle-branch block at the electrocardiogram and patients with LV diastolic dysfunction grade III. The following clinical data were collected: age, sex, weight, height, body mass index, presence of systemic arterial hypertension $(\mathrm{SAH})$, diabetes mellitus (DM), coronary artery disease (CAD), smoking status (current or former smokers) and dyslipidemia. SAH, DM, dyslipidemia and smoking status were either collected from patients' medical records or self-reported by patients. The diagnosis of SAH was defined by systolic and diastolic blood pressure $\geq 140 \mathrm{mmHg}$ and $90 \mathrm{mmHg}$, respectively, on two or more occasions, or use of anti-hypertensive drugs; ${ }^{\circ}$ and DM diagnosis was confirmed by: (1) symptoms of polyuria, polydipsia, weight loss and casual (at any time of day, regardless of the time since last meal) glucose $>200 \mathrm{mg} / \mathrm{dL}$; and (4) glycated hemoglobin $\mathrm{A} 1 \mathrm{c} \geq 6.5 \%$ or use of hypoglycemiant agents or insulin. ${ }^{9}$ Dyslipidemia was defined according to the $\checkmark$ Brazilian Guidelines on Dyslipidemias and Prevention of Atherosclerosis ${ }^{10}$ criteria - total cholesterol $>200 \mathrm{mg} / \mathrm{dL}$, high density lipoprotein cholesterol (HDL) $<40 \mathrm{mg} / \mathrm{dL}$ for men and $<50$ for women, low density lipoprotein cholesterol (LDL) $>160 \mathrm{mg} / \mathrm{dL}$, triglycerides $>150 \mathrm{mg} / \mathrm{dL}$ or use of lipid lowering drugs. The presence of CAD was confirmed by data from the medical records including: non-fatal myocardial infarction and surgical or percutaneous myocardial revascularization.

All patients signed the informed consent form in duplicate and kept one of the copies. The study was approved by the local ethics committee.

\section{Echocardiographic assessment}

Echocardiographic assessments with harmonic imaging were performed using the IE33 ${ }^{\mathrm{TM}}$ (Phillips), Envisor ${ }^{\mathrm{TM}}$ (Phillips) and Vivid $^{\mathrm{TM}}$ (GE) equipment. The tests were conducted by two echocardiographers experienced in TTE. The following parameters were collected for analysis: LV diastolic function (normal, grade I and grade II), presence of concentric or eccentric LVH, LAV, and RV systolic function measurements. Linear dimensions of the left atrial size were visualized from a parasternal long-axis window with two-dimensional and M-mode views. LAV was estimated using apical four- and two-chamber views, according to current recommendations. ${ }^{5-8}$ Only highly related variables were used for the LV diastolic function analysis to avoid false positive results - the peak early filling (E wave) and late diastolic filling (A wave) velocities (the $\mathrm{E} / \mathrm{A}$ ratio) <0.8; tissue Doppler imaging measured from the septal or lateral annulus ( $\mathrm{e}^{\prime}$ velocities) (septal $<7 \mathrm{~cm} / \mathrm{s}$ and lateral $<10 \mathrm{~cm} / \mathrm{s}$ ); average E/e' ratio $>14$; LAV index obtained from four- and two-chamber views $>34 \mathrm{~mL} / \mathrm{m}^{2}$; and peak tricuspid regurgitation velocity $>2.8 \mathrm{~m} / \mathrm{s}$. Classification of diastolic dysfunction was based on the analysis of the transmitral flow. A diastolic dysfunction grade I was defined as an $\mathrm{E} / \mathrm{A}$ ratio $<0.8$ and an E-wave $<50 \mathrm{~cm} / \mathrm{s}$, and dysfunction grade III defined as an E/A ratio $>2$. In case of an E/A ratio $<0.8$ and E-wave velocity $>50 \mathrm{~cm} / \mathrm{s}$, or an E/A ratio between 0.8 and 2 , other parameters were used for the evaluation: velocity of mitral regurgitation, $\mathrm{LAV}$, and $\mathrm{E} / \mathrm{e}^{\prime}$ ratio, according to current guidelines. ${ }^{11}$ LVH was categorized into concentric (increased LV mass index and increased relative wall thickness) and eccentric (increased LV mass index and normal relative wall thickness), according to relative wall thickness (normal $<0.42$ ) and indexed LV mass (normal $<95 \mathrm{mg} / \mathrm{m}^{2}$ for women and $<115 \mathrm{mg} / \mathrm{m}^{2}$ for men), according to current recommendations. ${ }^{5}$ Diameter of the right ventricle was measured in the parasternal long-axis window between the RV anterior wall and the interventricular septum in the ventriculo-aortic junction..$^{5-7}$ Two parameters were considered in the systolic function analysis: tricuspid annular plane systolic excursion (TAPSE) with M-mode (normal $>16 \mathrm{~mm}$ ) and lateral S' wave velocity by tissue Doppler imaging (normal $>9.5 \mathrm{~cm}$ )..$^{5-7}$ Patients were then divided into two groups: individuals with normal LV diastolic function $(\mathrm{n}=25)$ (control group) and individuals with LVDD grade I and II $(\mathrm{n}=25)$ (study group).

\section{Statistical analysis}

Quantitative variables were described as mean and standard deviation, median and interquartile ranges. Categorical variables were described as frequency and percentages. The Student's t-test was used for two-group comparisons of quantitative variables, and the Fisher's exact test used for categorical variables. Associations between variables were determined using the Pearson correlation coefficient. Normality of distribution of quantitative variables was tested by the Kolmogorov-Smirnov test. P-values $<0.05$ were considered statistically significant. All data were analyzed using the IBM SPSS Statistics software v.20.0 (Armonk, NY).

\section{Results}

Mean age of the control group was $49.9 \pm 16.3$ years and $52 \%$ of the individuals were men. Mean age of the study group was $67.1 \pm 10.6$ years $(p<0.001), 40 \%$ were men. A higher prevalence of $\mathrm{SAH}$ was seen in the study group than in the control group. Other clinical characteristics of participants are described in Table 1. The following variables showed normal distribution: TAPSE, lateral S' velocity, RV diastolic diameter, left atrial size and LAV. A higher incidence of LVH (concentric and eccentric) and a higher left atrial diameter were observed in the study group compared with the control group; no other differences were found between the groups (Tables 2 and 3). Considering the study group, patients with LVDD grade II showed significantly greater left atrial diameter and LAV compared with those with LVDD grade I, with no significant changes in the other parameters (Table 4). The type of LVH (concentric or eccentric) had no effect on the LA or other echocardiographic parameters (Table 4). There was a significant correlation of TAPSE and 


\section{Original Article}

Table 1 - Baseline characteristics of the study population

\begin{tabular}{|c|c|c|c|c|}
\hline \multirow{2}{*}{ Variable } & \multirow{2}{*}{ Classification } & \multicolumn{2}{|c|}{ Group } & \multirow{2}{*}{ p-value } \\
\hline & & Control $(n=25)$ & Study $(n=25)$ & \\
\hline Age (years) & Mean $\pm \mathrm{DP}$ & $49.9 \pm 16.3$ & $67.1 \pm 10.6$ & $<0.001$ \\
\hline \multirow{2}{*}{ Sex } & Male & $13(52 \%)$ & $10(40 \%)$ & \\
\hline & Female & $12(48 \%)$ & $15(60 \%)$ & 0.571 \\
\hline \multirow{2}{*}{ SAH } & No & $17(68 \%)$ & $5(20 \%)$ & \\
\hline & Yes & $8(32 \%)$ & $20(80 \%)$ & 0.001 \\
\hline \multirow{2}{*}{ DM } & No & $23(92 \%)$ & $18(72 \%)$ & \\
\hline & Yes & $2(8 \%)$ & $7(28 \%)$ & 0.138 \\
\hline \multirow{2}{*}{ Dyslipidemia } & No & $21(84 \%)$ & $18(72 \%)$ & \\
\hline & Yes & $4(16 \%)$ & $7(28 \%)$ & 0.496 \\
\hline \multirow{2}{*}{ CAD } & No & $25(100 \%)$ & $23(92 \%)$ & \\
\hline & Yes & $0(0)$ & $2(8 \%)$ & 0.490 \\
\hline \multirow{2}{*}{ Smoking } & No & $22(88 \%)$ & $21(84 \%)$ & \\
\hline & Yes & $3(12 \%)$ & $4(16 \%)$ & 1 \\
\hline
\end{tabular}

Results expressed as mean \pm standard deviation (SD) or frequency and percentage. * Student's t-test for independent samples (age); Fisher's exact test (categorical variables); $p<0.05$. SAH: systemic arterial hypertension; DM: diabetes mellitus; CAD: coronary artery disease

Table 2 - Baseline echocardiographic parameters in the study group and the control group

\begin{tabular}{|c|c|c|c|c|}
\hline Variable & Group & $\mathrm{n}$ & Mean \pm standard deviation & p-value* \\
\hline \multirow{2}{*}{ RV TAPSE (mm) } & Control & 25 & $22.3 \pm 2.0$ & \\
\hline & Study & 25 & $21.2 \pm 2.6$ & 0.103 \\
\hline \multirow{2}{*}{ RV lateral S' (cm/s) } & Control & 25 & $13.7 \pm 1.8$ & \\
\hline & Study & 25 & $13.2 \pm 1.7$ & 0.295 \\
\hline \multirow{2}{*}{ RVDD (mm) } & Control & 25 & $20.9 \pm 2.7$ & \\
\hline & Study & 25 & $22.0 \pm 3.2$ & 0.219 \\
\hline \multirow{2}{*}{ Left atrial size (mm) } & Control & 25 & $33.5 \pm 5.1$ & \\
\hline & Study & 25 & $37.3 \pm 5.5$ & 0.016 \\
\hline \multirow{2}{*}{ Left atrial volume $\left(\mathrm{ml} / \mathrm{m}^{2}\right)$} & Control & 25 & $29.2 \pm 5.5$ & \\
\hline & Study & 25 & $30.3 \pm 6.7$ & 0.508 \\
\hline
\end{tabular}

* Student's t-test for independent samples, $p<0.05 ; R V$ : right ventricular; TAPSE: tricuspid annular plane systolic excursion with M-mode; RVDD: right ventricular diastolic diameter.

lateral $\mathrm{S}^{\prime}$ of the right ventricle with LAV and size. A LAV $>34 \mathrm{~mL} / \mathrm{m}^{2}$ and left atrial size $>40 \mathrm{~mm}$ were associated with lower absolute values of TAPSE and RV lateral $S^{\prime}(p \leq 0.001$, $r=-0.4$ and -0.38 , respectively). There was a strong positive correlation of TAPSE with RV lateral $S^{\prime}(r=0.70, p<0.001)$, and of LAV and left atrial size $(r=0.89, p<0.01)$ (Tables 5 and 6, Figures 1 and 2).

\section{Discussion}

The role of the LAV as a sensitive index that reflects the severity of LV diastolic function and that provides prognostic information in many heart diseases has been well documented. ${ }^{4}$ However, its possible effect on RV performance still requires research. The present study demonstrated a significative inverse correlation of LAV and left atrial size with absolute values of TAPSE and RV lateral $\mathrm{S}^{\prime}$ in patients with LVDD.

In a similar study by Torii et al., ${ }^{12} 239$ patients with atrial fibrillation (AF) were compared with 281 individuals with sinus rhythm; AF patients showed lower TAPSE values regardless of age, sex, heart rate, LV ejection fraction and tricuspid regurgitation velocity. No correlations were made with LAV or left atrial size. Since we did not include patients with AF, it is possible to infer that an enlarged LA, per se, affects TAPSE and RV lateral $S^{\prime}$ only. It is known that left atrial enlargement does not occur uniformly due to physical limitations imposed by the sternum and spine, which can also affect dilatation and motion of the other cardiac chambers. ${ }^{4}$ TAPSE reflects not only the shortening of RV free wall, but also the traction 
Table 3 - Between-group comparison of baseline echocardiographic parameters in the study group and control group

\begin{tabular}{|c|c|c|c|c|}
\hline \multirow{2}{*}{ Variable } & \multirow{2}{*}{ Classification } & \multicolumn{2}{|c|}{ Group } & \multirow{2}{*}{ p-value* } \\
\hline & & Control $(n=25)$ & Study $(n=25)$ & \\
\hline \multirow{3}{*}{ LVDD } & Normal & $25(100 \%)$ & & \\
\hline & Grade I & & $21(84 \%)$ & \\
\hline & Grade II & & $4(16 \%)$ & - \\
\hline \multirow{3}{*}{ LVH } & Normal & $25(100 \%)$ & $19(76 \%)$ & \\
\hline & Concentric (c) & $0(0)$ & $5(20 \%)$ & \\
\hline & Eccentric (e) & $0(0)$ & $1(4 \%)$ & - \\
\hline \multirow{2}{*}{ LVH } & Normal & $25(100 \%)$ & $19(76 \%)$ & \\
\hline & Hypertrophy (c/e) & $0(0)$ & $6(34 \%)$ & 0.022 \\
\hline RV TAPSE (mm) & Normal (> 16) & $25(100 \%)$ & $25(100 \%)$ & \\
\hline \multirow{2}{*}{ RV lateral S' (cm/s) } & Normal $(>9.5)$ & $25(100 \%)$ & $25(100 \%)$ & \\
\hline & Altered $(\leq 9.5)$ & $0(0)$ & $0(0)$ & 1 \\
\hline \multirow{2}{*}{ RVDD (mm) } & Normal (16 a 30) & $25(100 \%)$ & $25(100 \%)$ & \\
\hline & Altered $(<16$ or $>30)$ & $0(0)$ & $0(0)$ & 1 \\
\hline \multirow{2}{*}{ Left atrial size (mm) } & Normal $(<40)$ & $23(92 \%)$ & $16(64 \%)$ & \\
\hline & Altered $(\geq 40)$ & $2(8 \%)$ & $9(36 \%)$ & 0.037 \\
\hline \multirow{2}{*}{$\operatorname{LAV}\left(\mathrm{ml} / \mathrm{m}^{2}\right)$} & Normal $(<34)$ & $20(80 \%)$ & $18(72 \%)$ & \\
\hline & Altered $(\geq 34)$ & $5(20 \%)$ & $7(28 \%)$ & 0.742 \\
\hline
\end{tabular}

Results expressed as frequency and percentage. Fisher's exact test (categorical variables); $p<0.05$. LVDD: left ventricular diastolic dysfunction; LVH: left ventricular hypertrophy; RV: right ventricular TAPSE: tricuspid annular plane systolic excursion with M-mode; RVDD: right ventricular diastolic diameter; LAV: left atrial volume

of the right ventricle resulting from LV contraction and effects of heart translation in the chest. ${ }^{13}$ Left atrial enlargement due to pressure and volume overload causes structural changes in the other chambers, including concomitant tricuspid annulus dilation, increased mobility of the tricuspid leaflets and tricuspid regurgitation. ${ }^{14,15}$ One hypothesis is that tricuspid annular dilatation, as a consequence of enlarged LA, could change TAPSE and lateral $S^{\prime}$ due to displacement of mitral annulus. This would result in RV remodeling and affect RV longitudinal shortening, as the site used for TAPSE and $\mathrm{S}^{\prime}$ measurements is the lateral insertion site of the tricuspid valve. However, we cannot rule out the possibility that such changes in cardiac chambers induced by the enlargement of the LA could also affect the ultrasonic angle beam, leading to changes in tissue Doppler imaging results. One interesting finding was that although the linear dimension of the LA was greater in the study group than in controls, LAV was practically normal in both groups. It is known that this linear measure of the LA has low accuracy and reproducibility due to technical limitations including the angle of the ultrasound beam, and the left atrial irregular geometry. ${ }^{4}$

It is also worth pointing out that the reference values for LAV are derived from international studies involving individuals with higher height; no study involving LAV measurements in a large Brazilian population has been performed so far. ${ }^{16}$ However, even small changes in the LAV caused changes in both TAPSE and RV lateral S' values.
Due to the strict exclusion criteria, no signs of RV dysfunction were expected in either study or control group. This was confirmed by the normal values of TAPSE and lateral $S^{\prime}$ of the right ventricle in all participants. In the study by Bruhl et al. ${ }^{17}$ evaluating 51 healthy individuals, with no past history of cardiac disease, found that TAPSE, mitral annular plane of systolic excursion (MAPSE), and tissue Doppler imaging measurements of the right and left ventricles were stable across age, gender, and body surface area. These findings illustrate the ventricular relationship and systolic interdependence. RV size and function correlate with the symptoms and physical capacity of patients with many clinical conditions. An accurate echocardiographic assessment of the right ventricle allows early detection of cardiac diseases, improves risk stratification and may indicate the right moment to start drug therapy. ${ }^{18,19}$ Zakir et al., ${ }^{20}$ addressed, appropriately and in detail, the correlation of LV diastolic function with RV systolic dysfunction, based on the invasive measurement of the pulmonary venous system. LV diastolic dysfunction causes an increase in left atrial filling pressure, which can be transmitted backwards, leading to pulmonary arterial hypertension and RV pressure overload. According to Simon et al. ${ }^{21}$ the first stage of RV dysfunction is pulmonary hypertension, which causes RV hypertrophy and ultimately right systolic dysfunction. However, in the present study, even patients with LVDD grade II showed normal TAPSE and RV lateral S'. In addition, difficulties in the analysis of the RV function may also result from RV 


\section{Original Article}

Table 4 - Echocardiographic parameters in the study group by left ventricular diastolic dysfunction grade and presence of concentric (c) and eccentric (e) left ventricular hypertrophy

\begin{tabular}{|c|c|c|c|c|}
\hline Variable & LVDD & $n$ & Mean \pm standard deviation & $\mathrm{p}$-value* \\
\hline \multirow{2}{*}{ RV TAPSE (mm) } & Grade I & 21 & $21.2 \pm 2.5$ & \\
\hline & Grade II & 4 & $21.5 \pm 3.5$ & 0.832 \\
\hline \multirow{2}{*}{$\mathrm{RV} \mathrm{S}^{\prime}(\mathrm{cm} / \mathrm{s})$} & Grade I & 21 & $13.2 \pm 1.7$ & \\
\hline & Grade II & 4 & $12.8 \pm 1.7$ & 0.604 \\
\hline \multirow{2}{*}{ RVDD (mm) } & Grade I & 21 & $21.5 \pm 3.2$ & \\
\hline & Grade II & 4 & $24.5 \pm 1.9$ & 0.085 \\
\hline \multirow{2}{*}{ Left atrial (mm) } & Grade I & 21 & $35.9 \pm 4.6$ & \\
\hline & Grade II & 4 & $44.5 \pm 4.4$ & 0.002 \\
\hline \multirow{2}{*}{$\operatorname{LAV}\left(\mathrm{ml} / \mathrm{m}^{2}\right)$} & Grau I & 21 & $29.0 \pm 5.5$ & \\
\hline & Grau II & 4 & $37.5 \pm 8.9$ & 0.017 \\
\hline Variable & LVH & $\mathrm{n}$ & Mean \pm standard deviation & $\mathrm{p}$-value* \\
\hline \multirow{2}{*}{ RV TAPSE (mm) } & Normal & 19 & $20.8 \pm 2.5$ & 0.176 \\
\hline & $\operatorname{LVH}(\mathrm{c} / \mathrm{e})$ & 6 & $22.5 \pm 2.8$ & \\
\hline \multirow{2}{*}{ RV S' (cm/s) } & Normal & 19 & $13.1 \pm 1.7$ & 0.580 \\
\hline & $\operatorname{LVH}(\mathrm{c} / \mathrm{e})$ & 6 & $13.5 \pm 1.8$ & \\
\hline \multirow{2}{*}{$\mathrm{RVDD}(\mathrm{mm})$} & Normal & 19 & $21.5 \pm 3.3$ & 0.185 \\
\hline & $\operatorname{LVH}(\mathrm{c} / \mathrm{e})$ & 6 & $23.5 \pm 2.8$ & \\
\hline \multirow{2}{*}{ Left atrial (mm) } & Normal & 19 & $36.3 \pm 5.2$ & 0.104 \\
\hline & $\operatorname{LVH}(\mathrm{c} / \mathrm{e})$ & 6 & $40.5 \pm 6.0$ & \\
\hline LAV $\left(\mathrm{ml} / \mathrm{m}^{2}\right)$ & Normal & 19 & $29.7 \pm 6.2$ & 0.413 \\
\hline
\end{tabular}

${ }^{*}$ Student's t-test for independent variables, $p<0.05$. RV: right ventricular; TAPSE: tricuspid annular plane systolic excursion with M-mode; RVDD: right ventricular diastolic diameter; LA: left atrium; LAV: left atrial volume

geometric and the complex correlation of the right ventricle with the LV septum. This could lead to delayed diagnosis of $\mathrm{RV}$ systolic dysfunction, which is generally detected in severe disease states. Therefore, serial analysis of the LAV and of TAPSE and lateral $S^{\prime}$ of the right ventricle in patients with LVDD or heart failure with preserved ejection fraction may provide initial evidence of deterioration of the RV function.

The other findings of the study were in accordance with literature data. In our study group, LVDD patients were older, showed higher incidence of LVH and greater left atrial size, and higher prevalence of SAH when compared with the control group. ${ }^{22-24}$ Patients with altered diastolic function had larger LA, which was positively associated with the degree of diastolic dysfunction. This is in line with the study by El Aouar et al. ${ }^{16}$

Regarding the high prevalence of SAH in the study group, it is well known that SAH can cause not only LVH but also RV hypertrophy ${ }^{25,26}$ that, in turn, was not assessed in our study. The fact that we did not find significant differences in echocardiographic measures between the groups can be explain by the strict exclusion criteria; it also reflects the fact that the analysis and referral values of echocardiographic parameters used in the assessment of the RV function is a matter of considerable debate in the literature, with wide variability within and between observers. ${ }^{6,7}$ In this sense, there is not a gold standard method, but rather a set of group that should be sequentially interpreted considering the clinical conditions of each patient. Thus, subtle changes in the variables used for RV function analysis in our study, as well as their correlation with left atrial enlargement can serve as a basis for future studies in this field. It is pertinent to consider the use of the speckle tracking technique (strain $[\varepsilon]$ and strain rate [SR or $\mathrm{s}^{-1}$ ) for assessment of the RV function in future studies. The $\varepsilon$ and $\mathrm{s}^{-1}$ indexes evaluate regional and global myocardial deformation with advantages over the use of the strain measure obtained from tissue Doppler, especially a lower variability within and between observers. The use of two-dimensional speckle tracking echocardiography allows the analysis of longitudinal, circumferential and radial strain, with not influence of the angle. ${ }^{27}$

Finally, this study has important limitations that should be considered: (1) the small number of the sample; studies involving larger sample sizes would be needed to confirm our findings; (2) the groups were not perfectly matched, especially in terms of age; (3) the lack of adequate or precise information about the time of hypertensive disease and its treatment, as well as on medications used by the patients; and (4) we did not analyze the variables tricuspid annulus diameter and right atrial volume, which could provide more information on the RV remodeling. In addition, patients with LVDD was composed of older individuals compared with the control group. This may have 
Table 5 - Echocardiographic parameters in the study group by left atrial size $(\mathrm{mm})$ and left atrial volume $\left(\mathrm{mL} / \mathrm{m}^{2}\right)$

\begin{tabular}{|c|c|c|c|c|}
\hline Variable & Left atrial size & $\mathrm{n}$ & Mean \pm standard deviation & p-value* \\
\hline \multirow{2}{*}{ RV TAPSE (mm) } & Normal $(<40)$ & 16 & $21.9 \pm 2.4$ & \\
\hline & Altered $(\geq 40)$ & 9 & $20.1 \pm 2.6$ & 0.103 \\
\hline \multirow{2}{*}{ RV lateral S' (cm/s) } & Normal $(<40)$ & 16 & $13.6 \pm 1.8$ & \\
\hline & Altered $(\geq 40)$ & 9 & $12.4 \pm 1.2$ & 0.111 \\
\hline \multirow{2}{*}{$\operatorname{RVDD}(\mathrm{mm})$} & Normal $(<40)$ & 16 & $21.7 \pm 3.2$ & \\
\hline & Altered $(\geq 40)$ & 9 & $22.4 \pm 3.3$ & 0.584 \\
\hline \multirow{2}{*}{$\operatorname{LAV}\left(\mathrm{ml} / \mathrm{m}^{2}\right)$} & Normal $(<40)$ & 16 & $26.8 \pm 3.8$ & \\
\hline & Altered $(\geq 40)$ & 9 & $36.7 \pm 6.2$ & $<0.001$ \\
\hline Variable & LAV & $\mathrm{n}$ & Mean \pm standard deviation & $p$-value* \\
\hline RV TAPSE (mm) & Normal $(<34)$ & 18 & $22.2 \pm 2.4$ & \\
\hline \multirow{2}{*}{ RV lateral S' (cm/s) } & Normal $(<34)$ & 18 & $13.7 \pm 1.7$ & \\
\hline & Altered $(\geq 34)$ & 7 & $11.9 \pm 0.7$ & 0.001 \\
\hline \multirow{2}{*}{ RVDD (mm) } & Normal $(<34)$ & 18 & $21.7 \pm 3.3$ & \\
\hline & Altered $(\geq 34)$ & 7 & $22.6 \pm 3.2$ & 0.565 \\
\hline \multirow{2}{*}{ Left atrial size (mm) } & Normal $(<34)$ & 18 & $34.7 \pm 3.6$ & \\
\hline & Altered $(\geq 34)$ & 7 & $43.9 \pm 4.0$ & $<0.001$ \\
\hline
\end{tabular}

*Student's t-test for independent samples, $p<0.05$. RV: right ventricular TAPSE: tricuspid annular plane systolic excursion with M-mode; RVDD: right ventricular diastolic diameter; LAV: left atrial volume.

Table 6 - Correlations between quantitative variables in the study group

\begin{tabular}{llcc}
\hline Variables & $\mathbf{n}$ & Pearson's correlation coefficient & p-value \\
\hline Age $\times$ RV TAPSE & 25 & -0.22 & 0.281 \\
Age $\times$ RV lateral S' & 25 & -0.42 & 0.035 \\
Age $\times$ RVDD & 25 & 0.04 & 0.866 \\
Age $\times$ left atrial size & 25 & 0.31 & 0.134 \\
Age $\times$ LAV & 25 & 0.40 & 0.050 \\
RV TAPSE $\times$ RV lateral S' & 25 & 0.70 & $<0.001$ \\
RV TAPSE $\times$ RVDD & 25 & 0.33 & 0.106 \\
RV TAPSE $\times$ left atrial size & 25 & -0.33 & 0.107 \\
RV TAPSE $\times$ LAV & 25 & -0.40 & 0.047 \\
RV lateral S' $\times$ RVDD & 25 & 0.40 & 0.051 \\
S' lateral VD $\times$ left atrial size & 25 & -0.26 & 0.216 \\
RV lateral S' $\times$ LAV & 25 & -0.38 & 0.063 \\
RVDD $\times$ left atrial size & 25 & 0.30 & 0.149 \\
RVDD $\times$ LAV & 25 & 0.23 & 0.271 \\
Left atrial size $\times$ LAV & 25 & 0.89 & $<0.001$ \\
\hline
\end{tabular}

TAPSE: tricuspid annular plane systolic excursion with M-mode; RVDD: right ventricular diastolic diameter; LAV: left atrial volume.

influenced the results, particularly the LAV. Also, the prevalence of SAH increases with age and differently in men and women..$^{28,29}$ Although the study group and the control group were not perfectly matched, the proportion of men and women was not different between the groups; yet, we did not find any significant difference between men and women in the study variables.

\section{Conclusions}

The present study determined, for the first time, a correlation of the increase in LAV with progressive RV functional changes in patients with LVDD. However, further studies are needed to confirm these findings. 


\section{Original Article}

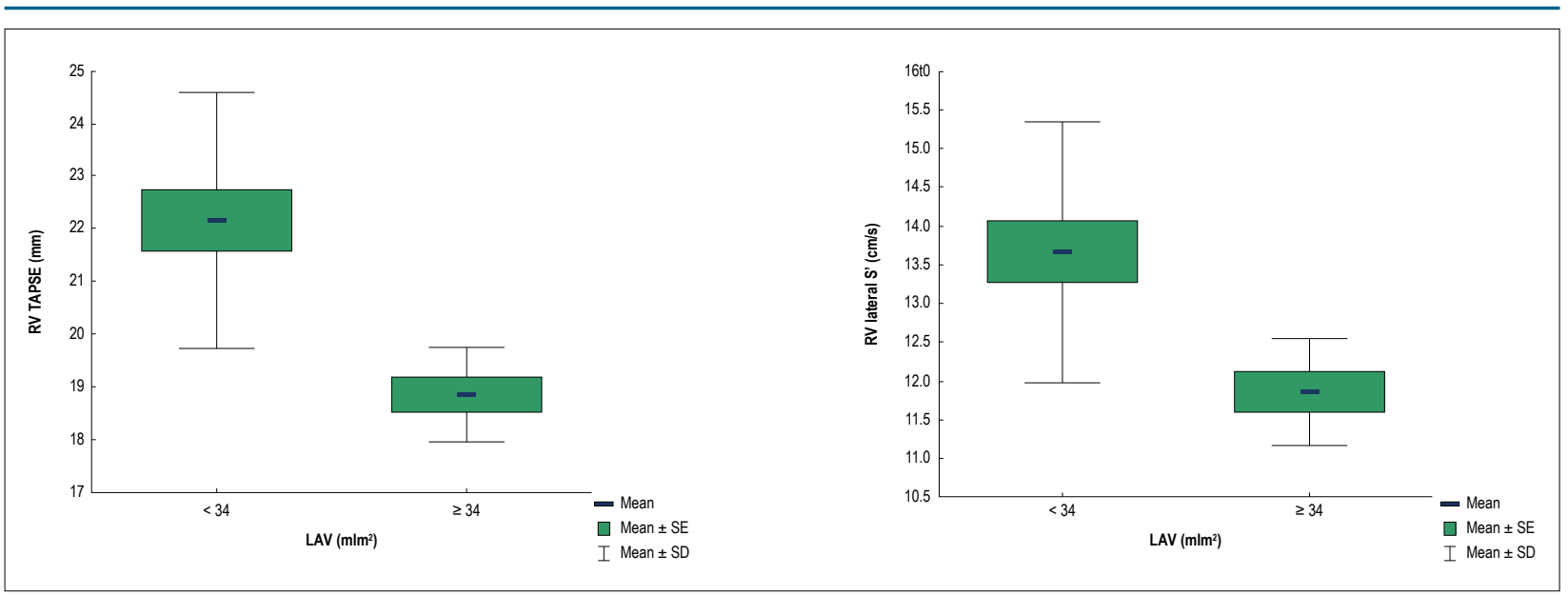

Figure 1 - Correlation between right ventricular tricuspid annular plane systolic excursion (RV TAPSE) and left atrial volume (LAV) (left panel; $p<0.001)$, and between lateral S' of the right ventricle and LAV (right panel; $p<0.001)$. RV: right ventricular; LA: left atrium; SE: standard error; SD: standard deviation; Student's t-test for independent samples; $p<0.05$.

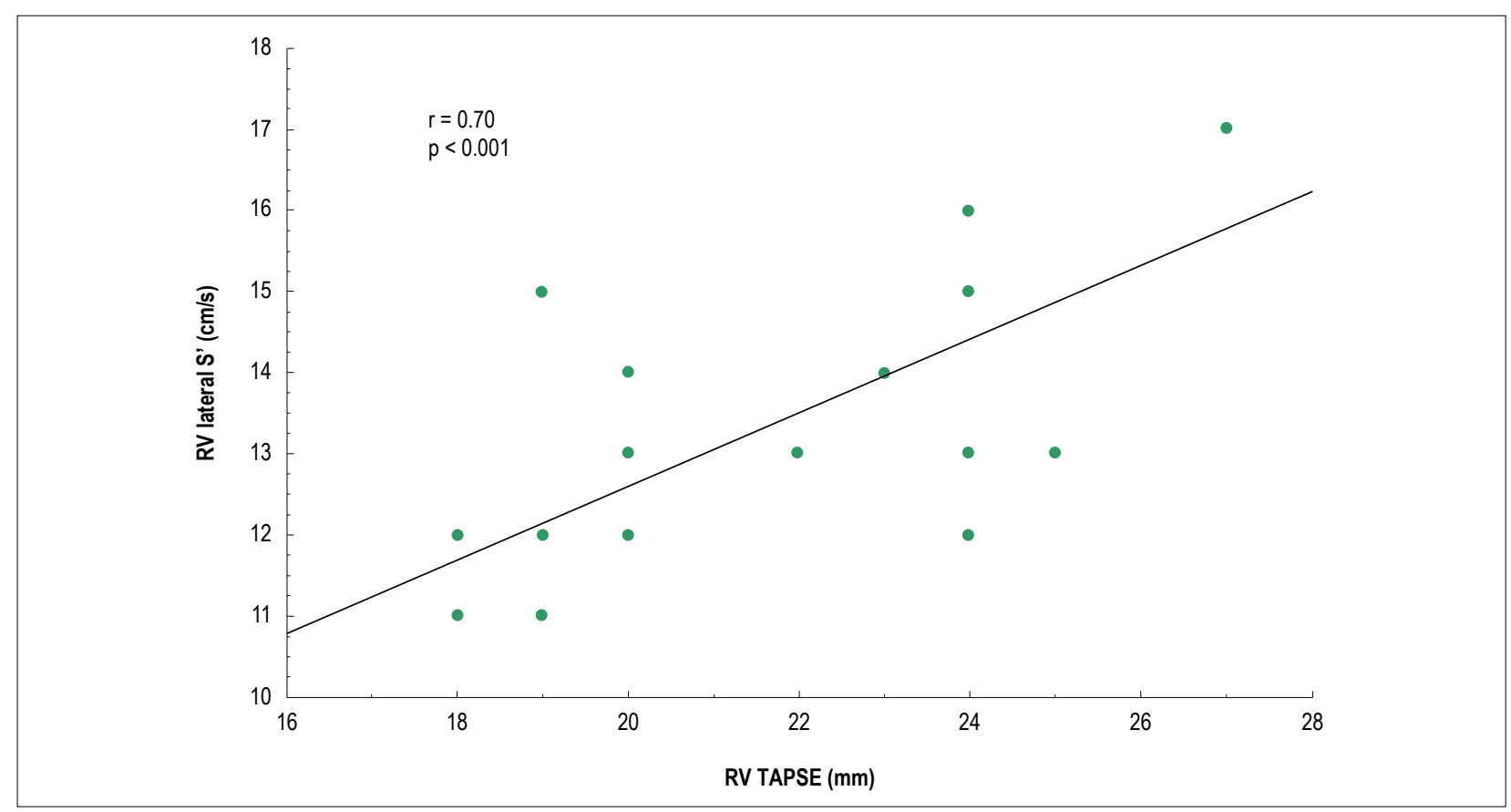

Figure 2 - Correlation between right ventricular tricuspid annular plane systolic excursion (RV TAPSE) and right ventricular S' lateral.

\section{Author contributions}

Conception and design of the research, acquisition of data and analysis and interpretation of the data: Baroncini LAV, Borges LJL, Camarozano AC, Carmo DC, Darwich RZ, Fortunato Junior JÁ; statistical analysis: Baroncini LAV; writing of the manuscript: Baroncini LAV, Darwich RZ, Fortunato Junior JÁ; critical revision of the manuscript for intellectual content: Baroncini LAV, Borges LJL, Camarozano AC, Carmo DC.

\section{Potential Conflict of Interest}

No potential conflict of interest relevant to this article was reported.

\section{Sources of Funding}

There were no external funding sources for this study.

\section{Study Association}

This study is not associated with any thesis or dissertation work.

\section{Ethics approval and consent to participate}

This study was approved by the Ethics Committee of the Universidade Positivo under the protocol number 2331223. All the procedures in this study were in accordance with the 1975 Helsinki Declaration, updated in 2013. Informed consent was obtained from all participants included in the study. 


\section{References}

1. Zile MR, Brutsaer DL. New concepts in diastolic dysfunction and diastolic heart failure: part I: diagnosis, prognosis, and measurement of diastolic function. Circulation. 2002;105(11):1387-93.

2. Hogg K, Swedberg K, McMurray J. Heart failure with preserved left ventricular systolic function; epidemiology, clinical characteristics, and prognosis. J Am Coll Cardiol. 2004;43(3):317-27.

3. Paullus WJ, Tschöpe C, Sanderson JE, Rusconi C, Flachskamp FA, Rademakers FE, et al. How to diagnose diastolic heart failure: a consensus statement on the diagnosis of heart failure with normal left ventricular ejection fraction by the Heart Failure and Echocardiography Associations of the European Society of Cardiology. Eur Heart J. 2007 ;28(20):2539-50

4. Sousa ACS. Left atrial volume as an index of diastolic function. Arq Bras Cardiol. 2006;86(3):e27-e33.

5. Lang RM, Badano LP, Mor-Avi V Afilalo J, Armstrong A, Ernande L, et al. Recommendations for cardiac chamber quantification by echocardiography in adults: an update from the American Society of Echocardiography and the European Association of Cardiovascular Imaging. J Am Soc Echocardiogr. 2015;28(1):1-39.e14.

6. Jurcut R, Giusca S, La Gerche A, Vasile S, Ginghina C, Voigt JU. The echocardiographic assessment of the right ventricle: what to do in 2010? Eur J Echocardiogr. 2010;11(2):81-96

7. Rudski LG, , Lai WW, Afilalo J, Hua L, Handschumacher MD, Chandrasekaran K, et al. Diretrizes para avaliação ecocardiográfica do coração direito em adultos: um informe da Sociedade Americana de Ecocardiografia. J Am Soc Echocardiogr. 2010;23:685-713.

8. James PA, Oparil S, Carter BL, 2014 Evidence-based guideline for the management of high blood pressure in adults : report from the panel members appointed to the Eight Joint National Committee (JNC 8). JAMA. 2014;311(5):507-20.

9. Standards of medical care in diabetes - 2015: summary of revisons. Diabetes Care. 2015; 38(Supp1):S4

10. Xavier HT, Izar MC, Faria Neto JR Assad M. H., Rocha V. Z., Sposito A. C., et al. V Diretriz Brasileira de Dislipidemias e Prevenção de Aterosclerose. Arq Bras Cardiol. 2013;101(4 Suppl 1):1-22.

11. Nagueh SF, Smiseth AO, Appleton CP Byrd BF 3rd, Dokainish H, Edvardsen $\mathrm{T}$, et al. Recommendations for the evaluation of left ventricular diastolic function by echocardiography: an update from the American Society of Echocardiography and the European Association of Cardiovascular Imaging. Eur Heart J Cardiovasc Imaging. 2016;17(12):1321-60.

12. Torii Y, Kusunose K, Yamada H, Nishio S, Hirata Y, Amano R, et al. Comparison of tricuspid annular plane systolic excursion in patients with atrial fibrillation versus sinus rhythm. Am J Cardiol. 2016; 117(2):226-32.

13. Lakatos B, Tősér Z, Tokodi M, Doronina A, Kosztin A, Muraru D, et al Quantification of the relative contribution of the different ventricular wall motion components to right ventricular ejection fraction: the ReVISION method. Cardiovascular Ultrasound. 2017;15(1):8.

14. Katsi V, Raftopoulos L, Aggeli C, Vlasseros I, Felekos I, Tousoulis D, et al. Tricuspid regurgitation after successful mitral valve surgery. Interact Cardiovasc Thorac Surg. 2012;15(1):102-8
15. Utsunomiya H, Itabashi Y, Mihara H, Berdejo J, Kobayashi S, Siegel RJ, et al. Functional tricuspid regurgitation caused by chronic atrial fibrillation: A real-time 3-dimensional transesophageal echocardiography study. Circ Cardiovasc Imaging. 2017;10(1):pii: e004897.

16. El Aouar LMM, Mayerfreud D, Magalhães P, Rodrigues SL, Baldo MP, Brasil $\mathrm{Y}$, et al. Relationship between left atrial volume and diastolic dysfunction in 500 Brazilian patients. Arq Bras Cardiol. 2013;101(1):52-8.

17. Bruhl SR, Chahal M, Khouri S. A novel approach to standard techniques in the assessment and quantification of the interventricular systolic relationship. Cardiovasc Ultrasound. 2011 Dec 20;9:42.

18. Kossaify A. Echocardiographic assessment of right ventricle, from the conventional approach to speckle tracking and three-dimensional imaging, and insights into the "right-way" to explore the forgotten chamber. Clin Med Insights: Cardiol. 2015 Jul 5;9:65-75.

19. Kjaergaard J, Iversen KK, Akkan D, Møller JE, Køber LV, Torp-Pedersen C, et al. Predictors of right ventricular function as measured by tricuspid anular plane systolic excursion in heart failure. Cardiovasc Ultrasound. 2009 Nov 4; 7:51.

20. Zakir R, Al-Dehneh A, Maher J, Saric M, Berkowitz R. Right ventricular failure in patients with preserved ejection fraction and diastolic dysfunction: an underrecognized clinical entity. Congest Heart Fail. 2007;13(3): 164-9.

21. Simon M, Pinsky MR. Right ventricular dysfunction and failure in chronic pressure overload. Cardiol Res Pract. 2011 Mar 23;2011:568095.

22. Vasan RS, Larson MG, Benjamin EJ, Evans JC, Reiss CK, Levy D. Congestive heart failure in subjects with normal versus reduced left ventricular ejection fraction: prevalence and mortality in a population-based cohort. J Am Coll Cardiol. 1999;33(7):1948-55

23. Fischer M, Baessler A, Hense HW, Hengstenberg C, Muscholl M, Holmer $\mathrm{S}$, et al.. Prevalence of left ventricular diastolic dysfunction in the community. Results from a Doppler echocardiographic-based survey of a population sample. Eur Heart J. 2003;24(4):320-8

24. Masoud FA, Havranek EP, Smith G, Fish RH, Steiner JF, Ordin DL, et al.. Gender, age, and heart failure with preserved left ventricular systolic function. J Am Coll Cardiol. 2003;41(2):217-23.

25. Gottdiener JS, Gay JA, Maron BJ, Fletcher RD. Increased right ventricular wall thickness in left ventricular pressure overload: echocardiographic determination of hypertrophic response of the nonstressed ventricle. J Am Coll Cardiol. 1985;6(3):550-5

26. Silva RP, Amodeo C, Ramires JAF. O ventrículo direito e a hipertensão arterial: aspectos ecocardiográficos. Arq Bras Cardiol. 2002;79(3):313-8.

27. Almeida ALC, Gjesdal O, Mewton N, Choi EY, Teixido-Tura G, Yoneyama K,et al.. Speckel-Tracking pela ecocardiografia bidimensional - aplicações clínicas. Rev Bras Ecocardiogr Imagem Cardiovasc. 2013;26(1):38-49.

28. Zabalgoitia M, Rahman SN, Haley WE, Mercado R, Yunis C, Lucas C, et al. Comparison in systemic hypertension of left ventricular mass and geometry with systolic and diastolic function in patients $<65$ to $>$ or $=65$ years of age. Am J Cardiol. 1998;82(5):604-8.

29. Sant'Anna MP, Mello RJ, Montenegro LT, Araújo MM. Left and right ventricular hypertrophy at autopsy of hypertensive individuals. Rev Assoc Med Bras. 201258(1):41-7. 
Right ventricle and left atrial volume

Original Article

(c) (†)

This is an open-access article distributed under the terms of the Creative Commons Attribution License 